\title{
Trend Analysis and Economic Effect of RTA Deaths on Dependency Ratio in Ghana
}

\author{
Ossei PPS ${ }^{\mathbf{1}}$, Agagli BM${ }^{1}$, Ayibor $\mathrm{WG}^{\mathbf{2}}$, Niako $\mathrm{N}^{\mathbf{1}}$ and Asante $\mathrm{E}^{\mathbf{1}}$ \\ ${ }^{1}$ Department of Pathology, KSMD, Kwame Nkrumah University of Science and Technology, Kumasi and Komfo Anokye Teaching Hospital, \\ Ghana \\ ${ }^{2}$ Department of Molecular Medicine, KSMD, Kwame Nkrumah University of Science and Technology, Ghana \\ *Corresponding Author: Ossei PPS, Department of Pathology, KSMD, Kwame Nkrumah University of Science and Technology, Kumasi, \\ Ghana.
}

Received: September 11, 2019; Published: September 27, 2019

DOI: 10.31080/ASPS.2019.03.0406

\section{Abstract}

Road traffic accident (RTA) injuries and mortalities are some side effects of using automobile vehicles and Ghana is not deprived of them. This study enlightens some effects of road traffic accident mortalities on the Ghanaian economy and investigates its yearly trend, age range distribution and also reveals its influence on economic activities. 832 secondary data obtained on individuals who died through RTA from the Autopsy day book of Pathology Unit, KATH was studied. 15\% (126) of the victims were children below 15 years $(\leq 14), 9 \%(78)$ are aged over than $64(\geq 65)$ years. The summed RTA deaths among these two economic dependent age ranges $(\leq 14+\geq 65)$ was $25 \%$ (204) and that of the economic active population (15 - 64) is $75 \%(628)$. Yearly trend plot shows fluctuations as the working group lies above the dependent population. There is 3:1 death ratio between the economic independent and dependent population respectively, contributing to high dependency ratio in Ghana. Support from the working group towards their families, society and any other dependent population decreases. Economic growth, development and GDP are negatively affected as tax revenue and productivity is comparatively decreasing. The Motor Transport and Traffic Unit should increase their effort to ensure discipline on roads.

Keywords: Road Traffic Accident; Active/Working Population; Dependency Ratio; Mortality; Economy

\section{Abbreviations}

RTA: Road Traffic Accident; MTTU: Motor Transport and Traffic Unit; GNI: Gross National Income; NRSS: National Road Safety Strategy.

\section{Introduction}

Collision of vehicles against each other and other objects on motorways and roads has been one of the leading causes of deaths and loss of resources. The effect of these various forms of road traffic accidents affect individuals and societies all over the world [1]. Some of the indicators contributing to most RTAs in Ghana includes indiscipline behaviors of road users (drivers on phone, pedestrians crossing road at wrong places), poor road network [2], driving under the influence of alcohol and bad vehicle conditions [1]. Having unlicensed and minors driving on our roads, drivers driving long distance without rest and chronically-ill (visually impaired persons) drivers are factors contributing to road traffic accidents on our roads. Over $65 \%$ of vehicles involved in accidents results from over-speeding and drivers failure to obey traffic signals [3]. As road traffic accident cases are predicted to increase to $80 \%$ in low and middle income countries $[4,5]$, it is also seen to be pronounced much more among the economic working force or active adults [68]. RTA is not limited to the immediate known problems of losing lives and properties but extends to influence some economic factors like working hours of a victim and his relatives, high dependence on relative's income, increase in government expenditure on emergency and medical cost, and loss of wages and productivity [9]. Despite government contribution to availing facilities and equipment for health services delivery, patients medical bills in Ghana according to Afukaar., et al. was estimated between $\$ 128.75$ and $\$ 328.85$, and $\$ 43.22$ and $\$ 85.40$ per urban area transport-related injury and rural area transport-related injury respectively, affecting Ghana's gross national income (GNI) [7]. The country's human resources is affected as domestic production decreases. Economic factors like savings is affected as medical payments becomes a shared responsibility of patient and their family [7]. The country also faces decline in its labor force as some RTA victims becomes morbid. Even though road traffic accident is an occupational hazard, Ghana over the years has strengthened systems and initiated activities like National Road Safety Strategy (NRSS) I, II, and III to ensure road safety. The 2016 report from Ghana national road safety commission informs comparatively to 2015 , an increase of $15.6 \%$ accidents but 
decrease in deaths [10]. Economic total dependency ratio is grossly the match of individuals not working to those in the labor force. A low dependency ratio indicates greater number of working population over the dependent population. When people working are of high number to support the non-working population with their needs, it reduce government expenditure on some social amenities [11]. The economic dependency ratio considers three age distribution; those below age 15 , those from age 15 to 64 , and those above age 64 . Those of the age ranges below 15 and above 64 are grouped and considered as the dependent population while the individuals from the age 15 to 64 is related to as the active or working population. A total economic dependency ratio is greatly influenced by many factors which includes road traffic accidents injuries and fatalities. The population size of the economic dependency distribution; the dependent or non-working population and active population or labor force are greatly affected by RTA deaths. 90\% of RTA occurs in low and middle income countries and they lose about $3 \%$ of their gross domestic product [12]. Economic development is examined to have a positive relationship with the growing number of traffic-related deaths, but it is also seems to stimulate adaptation mechanisms, such as improvements in the traffic infrastructure and trauma care [13].

\section{Data and Methods}

A secondary data of 832 RTAs death cases from Komfo Anokye Teaching Hospital, Pathology Unit Autopsy day book was extracted to examine the objective of this study. The hospital serves most the Ashanti region which contributed about $19.3 \%$ of the Ghana's total RTA fatalities in 2016 and the highest [10]. The hospital hence have information on most of the RTAs death cases in the region as it is the major referral hospital for most emergency cases. Only data with the following variables; the age of the victims, gender, nationality (Ghanaian) and having underling cause of death as RTA were extracted for this study. Data was compiled and analyzed with Microsoft excel 2013. Time series plot and analysis, percentage, ratio and proportion are some of the analysis tools employed to achieve the objectives of the study.

\section{Results}

\section{General distribution}

The mean age for the total number of deaths studied is 36 years. The modal age is 30 , with 40 frequencies. The youngest age is 0.3 year (15 weeks) and the oldest is 97 years. About $60 \%$ of the victims died as passengers, followed by $31 \%$ who died as pedestrians. From the autopsy day book, the most underlying cause of death was hemorrhagic shock which results from injuries victims obtain during the accidents. More than half of the people suffered from head, chest and abdominal injuries which accounted for loss of blood, leading to the above stated underlying causes of death.

\section{Age and gender distribution}

A total RTA death cases of 832 was studied by eight (8) different age ranges. Road traffic accident deaths is much mention among the age ranges 30-39 (21.75\%), 20-29 (20.19\%), and 40-49 (13.94\%) respectively. However, the aged individuals' engagement in road accident is less seen as the studied age range of 60-69 formed 6.25\%, and the aged above 69 years formed $6.85 \%$ of the total 832 RTA deaths studied. The sum of deaths among age ranges below 20 accounted to 163 (19.59\%), which is proportionately about one-fifth of the total death cases studied. These are summarized in table 1 below.

\begin{tabular}{|l|c|c|}
\hline Age Range & Frequency & Percentage \\
\hline$\leq 9$ & 86 & $10.34 \%$ \\
\hline $10-19$ & 77 & $9.25 \%$ \\
\hline $20-29$ & 168 & $20.19 \%$ \\
\hline $30-39$ & 181 & $21.75 \%$ \\
\hline $40-49$ & 116 & $13.94 \%$ \\
\hline $50-59$ & 95 & $11.42 \%$ \\
\hline $60-69$ & 52 & $6.25 \%$ \\
\hline$\geq 70$ & 57 & $6.85 \%$ \\
\hline Total & 832 & $100.00 \%$ \\
\hline
\end{tabular}

Table 1: Age Distribution of RTAs.

Figure 1 below shows the percentage presentation of males and females involvement in road traffic accidents. It shows men die more than women in RTA. 604 (72.6\%) men and women 227 (27.4\%).

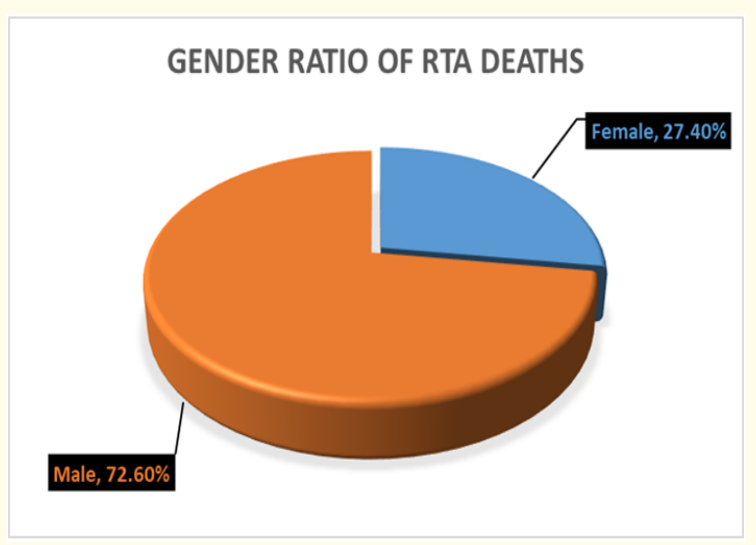

Figure 1:Gender ratio of deaths by Road Traffic Accidents.

\section{Economic dependency age categorization}

About $75 \%$ of the RTA death victims are of the economic working population, thus 15 to 64 years. Children below 15 years con- 
tribute $15.14 \%$ and those above 64 years also $9.38 \%$. Table 2 below shows a summary.

\begin{tabular}{|l|c|c|}
\hline \multicolumn{1}{|c|}{ Age Range } & Frequency & Percentage \\
\hline$\leq 14$ & 126 & $15.14 \%$ \\
\hline $15-64$ & 628 & $75.48 \%$ \\
\hline$\geq 65$ & 78 & $9.38 \%$ \\
\hline Total & 832 & 100.00 \\
\hline
\end{tabular}

Table 2: Economic Dependency Ratio Age Distribution.

Shown in Figure 2 above is a grouped dependent population (below 15 years and those above 64 years) and that of the labor force. Approximated percentage of 75 RTA death is mentioned in the economic active or working population with the remaining percentage of 25 from the dependent population. The sum of deaths for the two economic dependent population $(\leq 14$ and $\geq 65$ ) forms one-fourth of the total deaths.

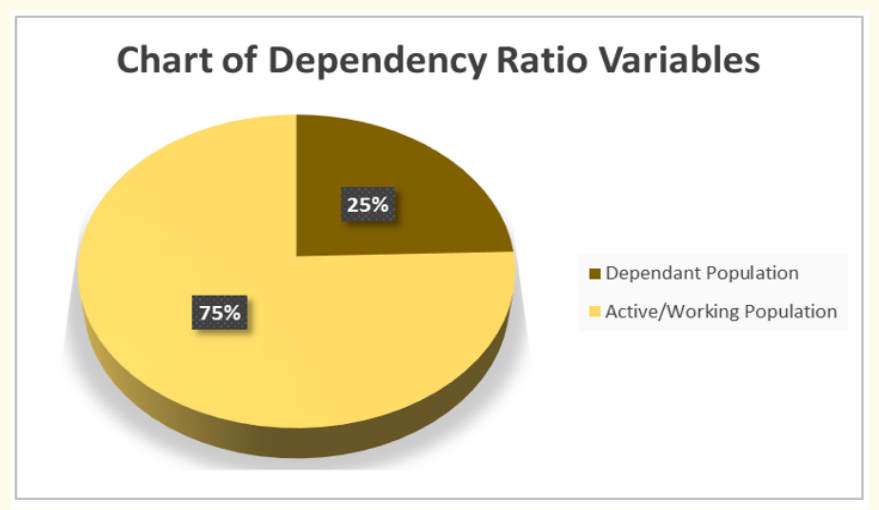

Figure 2: Economic Dependency Ratio Variables.

\section{Yearly trend analysis}

A yearly trend plot of the three economic age distribution shows fluctuation in the number of RTA deaths mentioned within the age groups, below 15, between 24 to 65 and that above 64 years over the period 2010 to 2016 . From figure 3 below which summarize the trend plots, the trend graph for economic working group is shown in blue. It had a frequency of 115 in 2010, but massively increased in 2011 to 158 . The number of deaths in 2012 significantly decreased below 80 and remained quiet stagnant in 2013. In 2014, RTA deaths among the working force increased to 100 and later fell below 60 in 2015. It kept a slight trail in 2016. The dependent age group below 15 years presented in green and the aged group presented in red both have the maximum points not above 40 . The number of RTA deaths among the children aged below 15 years reached its peak in 2011 at 40 and eventually fell below 20 in 2012. It slightly decreased in 2013 and later increased to 20 in 2014. It again dropped in 2015 and rose back to 20 in 2016. The number of deaths among the aged group ( $\geq 65$ ) looks to always lies below that of the children below 15 years except in 2015 where the equated. The yearly total of RTA deaths presented in orange shows a decreasing trend after the drastic rise in 2011 total cases. It has been sustained below 150 since the significant fall in 2012. Generally, the number of deaths mentioned in the working population lies far above the two dependent population. Number of RTA deaths among the active working group seems to be decreasing over the years despite the fluctuations. The total frequency of RTA deaths seem to be decreasing over the years, assuring more decrease in the future.

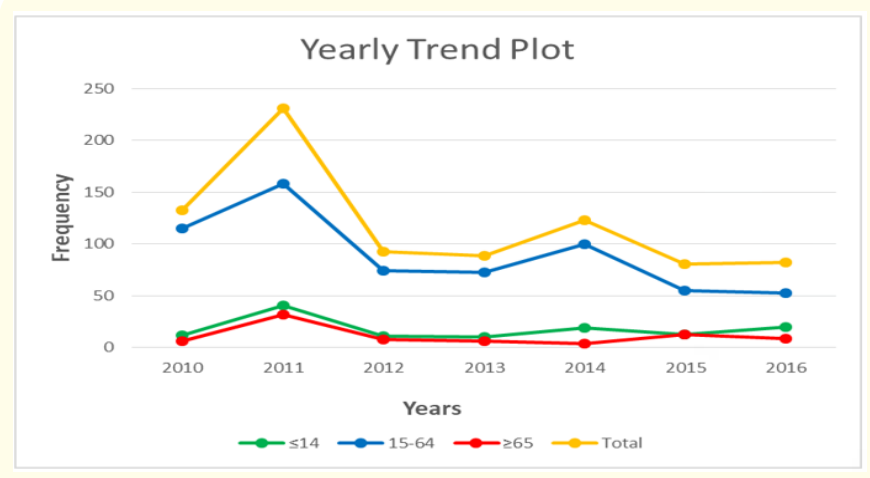

Figure 3: Yearly Trend Plot of Economic Dependency Ratio age distribution.

\section{Discussion}

Total life expectancy in Ghana is 63.4 according to the latest WHO data published in 2018. Life expectancy for Male 62.5, and females is 64.4 which gives Ghana a World Life Expectancy ranking of 155 [14]. With the country's life expectancy study, road traffic accident is found to be one of the leading cause of unnatural deaths in Ghana. An earlier study on "trend of medicolegal manner of deaths in Ghana" shows similar findings [15]. Out of the 832 studied RTA death cases, men are seen to be more affected than women with approximate ratio of 3:1. A related paper by Ivers., et al. and other studies stated similar results on men to women RTA death ratio on the road [12,16-19]. Men are more seen on the road with sociocultural reasons and high tendency of taking risk [16]. A study by the United Nations also shown that RTA is one of the leading cause of death among children [12]. Deaths among children (below 10) by RTA accounted for about $10 \%$ of the total RTA deaths in this study. About $50 \%$ of children dying on roads are killed as passengers [12]. The remaining proportion is shared among being a pedestrian, and other forms of road users. About two thirds of the global road traffic injury deaths among children occur in places including Africa[20]. Even though the International Monetary Fund (IMF) placed embargo on white collar jobs in the country, the World Bank's report on Ghana's labor force participation indicate an average value of 77.12 percent in 2018 and is the highest ever [21]. This informs that higher proportion of the active labor force are being employed in the private sector and the country's National Employment report affirms that [22]. 2015 labor force report from the 
Ghana Statistical Service informs 3\% of the country's labor force are commercial drivers. The private sector which is characterized by bad working conditions, uncertain work relationships and low wages still employs $80 \%$ of Ghana's labor force [23]. Male and female within the same working age of 15 to 60 years has $0.3 / 0.2$ probability of dying respectively [14], but income level, education level, age and occupation type has been studied to be the most influential factor to them deciding on the type of transport mode to patronize. Similar study reveal that "trotro" (commercial vehicle) is the main transport mode of choice in Ghana $[24,25]$. Deaths on the road among the age ranges 30-39, 20-29 and 40-49 in this study were very high. The above stated age groups recorded the highest frequencies of 181, 168, and 116 respectively. Related study by Hassan., et al. Wong., et al. Jha., et al. and other studies report similar findings about these age groups in relation to death on the road [5,16-19] Road traffic accident mostly kills the economic working population. A high proportion of road traffic accident victims are the bread winners of their households. They are the economic active workers in their families [25]. A study by the Center for Disease Control and Prevention on motor vehicle safety reveals that, in 2016, 2,433 young adult in the United State died on the road. Most developing countries, especially in Africa with relatively low vehicle densities are experiencing higher fatality rates than most industrialized countries. Relative countries like Nigeria and Kenya observed a five-fold increase in traffic-related fatalities over the last 30 years [26]. Developing countries account for $48 \%$ of motorized vehicles but contributes almost $90 \%$ of it fatalities [27]. A seven-year yearly trend viewed in respect of the three dependency ratio age groups; figure 3 in this paper shows that deaths on the road have been decreasing over the years. Among the working population, it decreases slowly with some fluctuations. A report from the Ghana transport commission on RTA shows that, accidents on the roads over the years are increasing but its mortality rate is decreasing [10]. Reference to some governmental intervention program like the Traffic System Risk (TSR) index and road safety campaigns has played significant roles in reducing deaths on the road [10]. Comparatively to other developing countries, rapid motorization, poor traffic management system and bad road network contribute to the disproportionate number of road traffic accidents [25]. The existence of unauthorized speed ramps, high speed motor traffic at pedestrian traffic like schools, bus stops, parks among other hinders accident avoidance [28]. This study reveals that deaths on the road among the economic active or working population is very high. It is three-fold that of the two non-economic active populations put together. Most of the non-economic active people comparatively patronizes our transport system at a low rate [16]. Their less engagement in economic activities relatively keeps them away from the road than those of the working group [16]. As individuals of the economic working population die 3-times more than those in the dependent populations, it affects the country's economy and result in high total dependency ratio [11]. In 2016, an estimate of 13.6 billion dollars was spent by the United States on issues of motor vehicle accidents, influencing government expenditure. The effect of RTA death ratio between the economic active and dependent population is not appreciable to economic dependency. Once the number of people in the working force decrease more than those in the economic dependent population, it causes an increment in the number of economic dependents [11]. This put more financial stress on the remaining working population. The working group has a greater responsibility of paying tax and their absence through death on the road influence the country's revenue mobilization. High dependency ratio relatively affects government expenditure especially on providing infrastructures for the dependent population. The decrease in the number of high taxpayers group will call for high taxes and government borrowing [29]. Some other economic factors like saving rate is affected by dependency ratio [30]. Dependency ratios are statistically significant and quantitatively important influencer of aggregate saving ratios. High dependency ratios among other important factors account for the great disparity between developed and underdeveloped countries [31]. Deaths on the road affect GDP, economic growth and development. Diminished productivity, loss of production hours of victims' and their relatives, medical cost, and premature mortality among others hinder economic growth [32]. Relative study has shown that, countries that fail to invest in road safety lose about 7 to $24 \%$ of their per capita GDP [12]. Reducing road traffic accident can boost economic growth. Earlier study on deaths and economic indicators estimates that, $10 \%$ reduction in road traffic deaths raises per capita real GDP by $3.6 \%$ on the average. Improving road safety intervention will not only benefit the society but macro economically, it will save huge economic tolls and human potentials. Limiting road traffic injuries and deaths plays a significant role in global development, with much benefits for public health, wellbeing, and economic growth [12].

\section{Conclusion}

The economic dependency ratio in Ghana is influenced by deaths on the road. The country faces issue of labor force declining as RTA injuries render its victims incapacitated. RTA over the years is increasing but its mortality is decreasing. Deaths on the road among men is three (3) times more than that for women. Men engage more in vehicular activities than the women and have high tendency of taking risk on the roads. Yearly trend analysis shows that RTA deaths is generally decreasing but it's much seen among economic working force than the dependent population. The death ratio of 3:1 among the economic independent and dependent population respectively influence total dependency ratio to be high in the country. Loosing high taxpayers through RTA diminishes productivity and economic development. The country's savings rate is influenced as victims of RTA burdens their relatives with medical bills and loss of economic working hours. The country's economic growth and development are affected as more human potentials are loss through deaths on the roads. Despite the Ghana government road safety interventions like Traffic System Risk (TSR) index 
and other road safety campaign activities which is positively influencing the number of deaths on the road [10], more interventions like double lane road and good traffic light system should be built to enhance the road transport system. Regular public education on road safety measures and driving when tired should be discouragement. The Motor Transport and Traffic Unit (MTTU) should increase force to ensure discipline on our roads.

\section{Acknowledgments}

The authors wish to acknowledge the contribution of the workers at department of Pathology, KATH for making available the autopsy reports and information contained in the Autopsy Day Book.

\section{Bibliography}

1. A Coleman. "Road Traffic Accidents in Ghana: A Public Health Concern, and a Call for Action in Ghana, (and the Sub-Region)". Open Journal of Preventive Medicine 4.11 (2014): 822-828.

2. SK Amedorme and S N Nsoh. "Analyzing the Causes of Road Traffic Accidents in Kumasi Metropolis". International Journal of Engineering Innovation and Research 3.6 (2016): 2277 5668.

3. S Ansari., et al. "Causes and effects of road traffic accidents in Saudi Arabia”. Public Health 114.1 (2000): 37-39.

4. AA Orowhigo and R Planning. "Socio-Economic Effects of Road Traffic Accident in Warri Metropolis, Delta State, Nigeria - a Nexus". 2.02 (2017): 38-56.

5. P Poku and S Ossei. "Review of the Various Forms of Injuries on Drivers Involved in Road Traffic Accidents (RTA)". (2017).

6. Oppong. "Statistical analysis of road accidents fatality in ghana using poisson regression by Oppong, Richard Asumadu A Thesis submitted to the Department of Mathematics, Kwame Nkrumah University of Science and Technology in partial fulfillment of the requiremen". (2012).

7. FK Afukaar., et al. "Pattern of road traffic injuries in Ghana: Implications for control”. 10.1-2 (2003): 69-76.

8. L UB., et al. "Occupational Health Hazards among Commercial Motorcyclists in Ahmadu Bello University, Zaria”. IOSR 3.1 (2014): 46-52.

9. D R K Gorea. "Financial impact of road traffic accidents on the society". International Journal of Ethics, Trauma and Victimology 2.1 (2016): 6-9.

10. R Traffic., et al. "National road safety commission Ghana road fund secretariat". (2017).

11. "Dependency ratio". (2010): 3-6.
12. R Ivers., et al. "Road Traffic Injuries". in International Encyclopedia of Public Health, Elsevier (2017): 393-400.

13. EF van Beeck., et al. "Economic development and traffic accident mortality in the industrialized world, 1962-1990". International Journal of Epidemiology 29.3 (2000): 503-509.

14. "WHO | Ghana”. WHO (2019).

15. Paul., et al. "Trend of Medicolegal Manner of Deaths in Ghana : A Forensic Autopsy-Based Trend of Medicolegal Manner of Deaths in Ghana: A Forensic Autopsy-Based Study". (2017).

16. T T Peden. "Youth and road safety". WHO Press. World Health Organization 11.4 (2007): 425-432.

17. NHassan. "Epidemiological Study of Road Traffic Accident Cases: A Study from Bengazy-Libya". Forensic Science Today 29 (2018): 007-013.

18. E Wong., et al. "Road traffic accident mortality in Singapore". Journal of Emergency Medicine 22.2 (2002): 139-146.

19. N Jha., et al. "Injury Pattern Among Road Traffic Accident Cases : a Study From South India". Indian Journal of Community Medicine 28 (2003): 85-90.

20. E. Asia. "Children and road traffic injury". (2004).

21. Ghana Labor force participation - data, chart | The Global Economy.com.

22. K Anthony., et al. "National Employment Report" Final 24-516.

23. C Osei-Boateng and E Ampratwum. "The Informal Sector in Ghana". Journal of Urban Planning and Development 27.3-4 (2011): 355-392.

24. D E Hotor. "The use of Public Transport Services by Residents in the Accra Metropolitan Area". (2016).

25. V M Nantulya. "The neglected epidemic: road tr". BMJ 324.7346 (2012): 1139-1141.

26. W Odero., et al. "Road traffic injuries in developing countries: a comprehensive review of epidemiological studies". Tropical Medicine and International Health 2.5 (1997): 445-460.

27. U Schmucker., et al. "Verkehrsunfälle in entwicklungsländern". Unfallchirurg 113.5 (2010): 373-377.

28. EA Vasconcellos and S Paulo. "Traffic accident risks in developing countries: superseding biased approaches Current conditions A social perspective: who hits who". (2005): 1-11. 
29. A Razin., et al. "The Aging Population and the Size of the Welfare State The Aging Population and the Size of the Welfare State Assaf Razin". 110.4 (2014): 900-918.

30. D Economics. "Pakistan Institute of Development Economics, Islamabad Dependency Ratio, Foreign Capital Inflows and the Rate of Savings in Pakistan with Comments. Author (s): Ashfaque H. Khan, Lubna Hasan, Afia Malik and Beatrice Knerr Source: The Pakistan De". 31.4 (2019).

31. American Economic Association Dependency Rates and Aggregate Savings: A New International Cross-Section Study Author (s): Rati Ram Source: The American Economic Review 72.3 (1982): 537-544.

32. J Sachs and P Malaney. "The economic and social burden of malaria”. Nature 415.6872 (2002): 680-685.

Volume 3 Issue 10 October 2019

(C) All rights are reserved by Ossei PPS., et al. 